\title{
The Political Economy of Sin Taxes
}

\author{
Markus Haavio \\ Bank of Finland and HECER \\ and \\ Kaisa Kotakorpi \\ University of Tampere
}

Discussion Paper No. 185

September 2007

ISSN 1795-0562

HECER - Helsinki Center of Economic Research, P.O. Box 17 (Arkadiankatu 7), FI-00014 University of Helsinki, FINLAND, Tel +358-9-191-28780, Fax +358-9-191-28781, E-mail info-hecer@helsinki.fi, Internet www.hecer.fi 


\title{
The Political Economy of Sin Taxes*
}

\begin{abstract}
We analyse the determination of taxes on harmful goods when consumers have selfcontrol problems. We show that under mild conditions, the socially optimal tax rate exceeds the average distortion caused by self-control problems. Further, we show that in most cases the tax rate chosen in political equilibrium is below the socially optimal level.
\end{abstract}

JEL Classification: H21, H30, D72.

Keywords: Excise taxation, voting, self-control.

$\begin{array}{ll}\text { Markus Haavio } & \text { Kaisa Kotakorpi } \\ \text { Bank of Finland } & \text { Department of Economics and Accounting } \\ \text { P.O. Box } 160 & \text { University of Tampere } \\ \text { FI-00101 Helsinki } & \text { FI-33014 University of Tampere } \\ \text { FINLAND } & \text { FINLAND }\end{array}$

e-mail: markus.haavio@bof.fi_e-mail: kaisa.kotakorpi@uta.fi

* We would like to thank Essi Eerola, Jukka Pirttilä, Panu Poutvaara and Theis Theisen as well as seminar participants at the 1st World Meeting of the Public Choice Society, the 63rd Congress of the International Institute of Public Finance, and at HECER for comments. This work was initiated while Kotakorpi was visiting the LSE. Kotakorpi thanks the LSE and STICERD for their hospitality, as well as Tim Besley and Erik Eyster for helpful comments on an early version of the paper. All remaining errors are ours. Kotakorpi gratefully acknowledges financial support from the FDPE, the European Commission and the EDNET network, Yrjö Jahnsson Foundation and the Foundation for Economic Education. 


\section{Introduction}

We analyse the determination of taxes on goods whose current consumption causes utility costs (for example negative health effects) in the future. When consumers have timeinconsistent preferences, they consume too much of such goods. Using "sin taxes" to correct distortions in the consumption of harmful goods when consumers have self-control problems has also been considered in O'Donoghue and Rabin (2003; 2006).

Market-based mechanisms for correcting the distortion caused by self-control problems are likely to be ineffective (see Köszegi (2005)), and consumers might thus value sin taxes as a commitment device. In addition to the monetary cost of taxation, sin taxes affect individual utility due to the corrective nature of the tax when preferences are time-inconsistent. If this positive effect outweighs the monetary cost, sin taxes can improve individual welfare - see Gruber and Köszegi (2004) and Kotakorpi (2006) for theoretical analyses and Gruber and Mullainathan (2005) for empirical evidence.

The purpose of the current paper is two-fold. Firstly, we contribute to the discussion on optimal sin taxes by deriving an explicit rule for the optimal tax in a second-best setting where individuals differ in their degree of self-control problems. Secondly, we examine how sin taxes are determined in political equilibrium, a question that has to our knowledge not yet been analysed in the literature.

Many economists have been concerned that sin taxes as well as other paternalistic policies that are aimed at helping irrational individuals ${ }^{1}$ are often detrimental for the welfare of rational individuals. ${ }^{2}$ This has resulted in an emphasis on the search for policies that help irrational individuals while having only a small or no impact on those who are rational. ${ }^{3}$ However, there has recently been an interest in moving beyond studying minimal interventions, to studying optimal paternalistic policies. Our analysis is particularly closely related in this respect to O'Donoghue and Rabin (2006). ${ }^{4}$

When individuals differ in their degree of self-control problems but a uniform sin tax is applied, we are necessarily in a second-best situation. We analyse the trade-off between benefits to irrational individuals and costs to rational individuals further, and find the optimal balance between them: we provide an explicit formula for the second-best optimal sin tax

\footnotetext{
${ }^{1}$ Throughout the paper, we refer to individuals with a self-control problem as irrational, as they behave in an inconsistent manner and make consumption decisions that fail to maximise their own life-time utility. Similar terminology has been used for example by O'Donoghue and Rabin (2006).

${ }^{2}$ Beyond this concern, some economists remain sceptical about paternalism for more general reasons - see for example Glaeser (2006) for a critical view. For example, the possibility of government failure may reduce the effectiveness and desirability of paternalistic policies. Despite the importance of this consideration, we abstract from this issue in the current paper. On the other hand, we show that in our model consumers would themselves vote for paternalistic policies: such policies can therefore be the outcome of a democratic decision making process, which has interesting implications for the justification of paternalism.

${ }^{3}$ See for example Camerer et al (2003), Thaler and Sunstein (2003) and O'Donoghue and Rabin (1999).

${ }^{4}$ O'Donoghue and Rabin (2006) examine the conditions under which the optimal sin tax is positive, and whether sin taxes can yield Pareto improvements (compared to zero taxes). They further provide comparative statics of the optimal sin tax when there are changes in the distribution of self-control problems and tastes.
} 
and show that it exceeds the mean distortion in consumption. The reason is right at the heart of the recent discussion on paternalism: for reasonable assumptions about the form of the demand function, sin taxes have a relatively small (negative) effect on the utility of (close to) rational individuals, who consume relatively little of the good. On the other hand, irrational consumers with a very high level of consumption gain a lot from sin taxes.

We then turn to analyse the majority voting equilibrium when individuals differ in their degree of self-control problems. We assume that individuals are fully aware of their self-control problem, and vote on the sin tax to be implemented from the next period onwards. Taxation can then provide a commitment device that helps individuals move their consumption closer to its optimal level.

As a benchmark, we consider the case where tax revenue is distributed back to consumers in such a way that the redistributive effects of taxation are eliminated. In this setting individuals prefer the level of taxes that completely eliminates the distortion in their own consumption, and the political equilibrium is the tax rate that corresponds to the median level of self-control problems. We show that equilibrium taxes are in most cases below the socially optimal level. The reason is that the asymmetric effect of sin taxes at different ends of the distribution of self-control problems is not taken into account by the median voter. However, in this setting where sin taxes have no redistributive effects, there is one particular case where the equilibrium and the social optimum coincide: this is when consumption is so harmful that the optimal level of consumption is zero even in the absence of taxation. In this case, it is in the interests of both the consumers and the social planner to eliminate all consumption.

We then proceed to analyse the case where the redistributive effects of sin taxes are taken into account. This case is the one that is more relevant from a practical point of view, and also highlights some interesting new issues. On the one hand, an individual without self-control problems will prefer a low tax, as high taxation would cause an unnecessary distortion in consumption from his point of view. On the other hand, however, sin taxes will redistribute income from irrational large-scale consumers to rational consumers, a reason for consumers with no self-control problems to vote for a high tax.

Despite these counteracting motives that affect an individual's preferred tax rate, we show that a majority voting equilibrium exists in our model also in this case, and corresponds to the tax rate preferred by the individual with the median level of self-control problems. Importantly, we show that when redistributive effects of sin taxes are taken into account, the equilibrium tax rate is below the socially optimal level regardless of the level of harm from consumption. The redistributive motive for taxation implies that equilibrium taxes are below the social optimum even when consumption is extremely harmful: the median voter does not consume the good in equilibrium, and simply wants to maximise redistribution from irrational individuals towards himself. On the other hand, the social planner wants to completely eliminate consumption. It is worth emphasising that our results regarding extremely harmful 
consumption goods are very robust to different functional form assumptions and do not depend on the distribution of self-control problems.

One of the aims of our analysis is to contribute to the policy discussion on the taxation of harmful goods. In European countries, tobacco products are taxed much more heavily than alcohol: the excise duty on the most popular brand of tobacco was on average approximately $60 \%$ of the total retail price in the EU-15 member states in 2003 (Cnossen and Smart 2005), whereas the corresponding figure was $19 \%$ for beer, $14 \%$ for wine and $39 \%$ for spirits (WHO 2004). ${ }^{5}$ It might appear that cigarette taxes are too high from a social point of view, particularly as cigarette taxes in most countries seem to exceed the external costs of smoking (Cnossen and Smart 2005) ${ }^{6}$. However, considering not only negative externalities, but also harm experienced but not taken into account by the consumer himself, optimal taxes should indeed exceed the level that would be appropriate if only externalities were taken into account. As our analysis shows, the redistributive motive for taxation implies that equilibrium taxes on highly harmful goods such as cigarettes may be too low from a social point of view. ${ }^{7}$

In addition to the previous literature on taxation when consumers have self-control problems, our analysis has some similarities with the analysis of commodity taxation in the presence of externalities: negative health effects (in the case of consumers with self-control problems) as well as negative externalities are both harmful effects not taken into account by consumers, and governments might wish to alleviate these effects through taxation. Diamond (1973) has analysed optimal taxation of externality-generating goods when individuals give rise to different (marginal) externalities. ${ }^{8}$ In the case of externalities, however, there is no natural assumption to make about how the magnitude of the marginal externality should be correlated with individual demand. In our context, on the other hand, a high marginal internality is naturally associated with high consumption, since consumers with a more severe self-control problem have a higher level of consumption, ceteris paribus. This correlation is the mechanism that drives many of the key results in this paper.

The rest of the paper proceeds as follows. We introduce the model in Section 2 and derive the second-best optimal sin tax in Section 3. The political equilibrium is analysed in Section 4 , where we first study the benchmark case where sin taxes have no redistributive effects, and then extend the analysis to account also for the redistributive effects of sin taxes. Section 5 shows that our main conclusions extend to the case where sin taxes are also used for revenue

\footnotetext{
${ }^{5}$ The figures for alcoholic drinks were calculated using data for 9 countries only, as the figures for the rest of the EU-15 were not reported (see WHO 2004, 54). The average total tax collections in the EU-15 member states were approximately 100 euros per adult in the case of alcohol, and around 280 euros per capita in the case of tobacco (see for example Cnossen (2006a) and (2006b)).

${ }^{6}$ In the case of alcohol, on the other hand, taxes appear to be lower than the level that would be mandated even by externality considerations alone (Cnossen 2006a)

${ }^{7}$ The relatively low prevalence of smoking suggests that cigarettes fit our category of highly harmful substances (where most people abstain from consumption): smoking prevalence is around 20-30\% in most EU countries, whereas only around $15 \%$ of adult Europeans abstain from alcohol consumption (Anderson and Baumberg 2006, European Commission 2004).

${ }^{8}$ See Eerola and Huhtala (2007) for a recent contribution to the literature on the political economy aspects of environmental policy.
} 
raising purposes. Section 6 concludes.

\section{The model}

We consider a model where consumers have a quasi-hyperbolic discount function (Laibson 1997), using a set-up that is similar to O'Donoghue and Rabin (2003; 2006). Life-time utility of an individual is given by

$$
U_{t}=\left(u_{t}, \ldots, u_{T}\right)=u_{t}+\beta_{i} \sum_{s=t+1}^{T} \delta^{s-t} u_{s}
$$

where $\beta_{i}, \delta \in(0,1)$ and $u_{t}$ is the periodic utility function. Individuals are therefore assumed to be identical in all other respects, but they differ in their degree of quasi-hyperbolic discounting. We assume that the quasi-hyperbolic discount factor $\beta$ has a distribution function $F(\beta)$ with mean $E(\beta)$ and median $\beta_{\text {med }}$. Throughout the paper we consider the general case where $\beta$ has the support $\left[\beta_{L}, \beta_{H}\right]$, with $0 \leq \beta_{L}<\beta_{H} \leq 1$. Quasi-hyperbolic discounting implies that preferences are time-inconsistent: discounting is heavier between today and tomorrow, than any two periods that are both in the future.

We assume that individuals derive utility from a composite good $(z)$, which is taken as the numeraire, and another good $(x)$ which is harmful in the sense that it yields positive utility in the short-run, but has some negative effects in the long-run. Specifically, we assume that periodic utility is given by

$$
u_{t}\left(x_{t}, x_{t-1}, z_{t}\right)=v\left(x_{t}\right)-h\left(x_{t-1}\right)+z_{t},
$$

where $v^{\prime}>0, v^{\prime \prime}<0$ and the harm function ${ }^{9}$ is characterised by $h^{\prime}>0$ and $h^{\prime \prime} \geqslant 0$.

We assume that there is no borrowing or lending. In each period, consumers then choose $x$ to maximize $\mathrm{e}^{10} u(x)=v(x)-\beta_{i} \delta h(x)+z$ subject to a per-period budget constraint $q x+z \leq$ $B+S$. We assume that product markets are competitive and normalise the producer price to 1 , and $q=1+\tau$ denotes the consumer price of good $x$. $B$ is the consumer's income (taken to be exogenous) and $S$ is a possible lump-sum subsidy received by the consumer from the government. Taxes and subsidies will be modelled in more detail in later sections. Given the above specification, the demand for good $x$ satisfies

$$
v^{\prime}\left(x^{*}\right)-\beta_{i} \delta h^{\prime}\left(x^{*}\right)=q .
$$

\footnotetext{
${ }^{9}$ As in O'Donoghue and Rabin (2006), we assume that the marginal benefits and marginal costs of consumption are independent of past consumption levels. In such a setting, it is not essential that the harm is modelled as occuring only in the period following consumption - $h$ can be thought of as the discounted sum of harm occurring in all future periods. See Gruber and Köszegi (2004) for an analysis where past consumption affects current marginal utility.

${ }^{10}$ We have dropped the time index $t$, since with our specification consumption is constant accross periods.
} 
However, the time-inconsistency in preferences implies that the consumer would like to change his behaviour in the future: from the next period onwards, the consumer would like to choose consumption levels that maximise ${ }^{11} u^{o}(x)=v(x)-\delta h(x)+z$. We take this long-run perspective as the one relevant for welfare evaluation - this has become a standard choice in the literature on sin taxes (see for example Gruber and Köszegi (2004), O'Donoghue and Rabin $(2003 ; 2006))$. There are clear reasons that justify this choice of welfare criterion: Firstly, we assume that taxes are implemented from the period after the policy decision is made. Therefore, consumers themselves agree that $u^{o}(x)$ is the relevant utility function, and voting decisions will be made based on maximising this function. We thus use the same criterion consistently when deriving both the optimum and the equilibrium level of taxes. Further, $u^{o}(x)$ is the utility function that applies to all periods except for the present one. Since we consider an infinite number of periods, the weight of any single period should be negligible as long as periods are sufficiently short ${ }^{12}$. This latter consideration applies irrespective of the timing of the model.

The optimal level of consumption therefore satisfies $v^{\prime}\left(x^{o}\right)-\delta h^{\prime}\left(x^{o}\right)=q$ : because of quasi-hyperbolic discounting $(\beta<1)$, the equilibrium level of consumption of the harmful good $\left(x^{*}\right)$ is higher than the optimal level $\left(x^{o}\right)$.

\section{The second-best optimal sin tax}

We argued above that long-run utility is the appropriate welfare criterion in our model. The social welfare function is then given by $W(q) \equiv \int_{\beta_{l}}^{\beta_{H}} G(V(q ; \beta)) f(\beta) d \beta$, where $V(q ; \beta)$ is the long-run indirect utility function. We assume that the function $G($.$) is utilitarian, and$ the social welfare function therefore becomes

$$
\begin{gathered}
W(q)=\int_{\beta_{l}}^{\beta_{H}} V(q ; \beta) f(\beta) d \beta=E_{\beta}[V(q ; \beta)] \\
=E_{\beta}\left[v\left(x^{*}(q ; \beta)\right)-\delta h\left(x^{*}(q ; \beta)\right)-q x^{*}(q ; \beta)+S(q, \beta)\right]+B,
\end{gathered}
$$

where $x^{*}$ satisfies (3) and is therefore distorted whenever $\beta<1$, as argued above. Taking into account the government's budget constraint $\tau E_{\beta}\left[x^{*}(q ; \beta)\right]=E_{\beta}[S(q, \beta)]$, the social welfare function can be written as

$$
W(q)=E_{\beta}[V(q ; \beta)]=E_{\beta}\left[v\left(x^{*}(q ; \beta)\right)-\delta h\left(x^{*}(q ; \beta)\right)-x^{*}(q ; \beta)\right]+B .
$$

Given the distortion in consumption caused by quasi-hyperbolic discounting, the government may consider imposing a sin tax on harmful goods as a corrective measure. The social

\footnotetext{
${ }^{11}$ See equation (1) and think of a consumer in period $t$, making consumption decisions for period $t+1$ onwards.

${ }^{12}$ See also Bernheim and Rangel $(2007,4)$ for a discussion on this point.
} 
planner's first-order condition is

$$
\begin{gathered}
E_{\beta}\left[\frac{\partial V(q ; \beta)}{\partial q}\right]=E_{\beta}\left[\left[v^{\prime}\left(x^{*}(q ; \beta)\right)-\delta h^{\prime}\left(x^{*}(q ; \beta)\right)-1\right] \frac{\partial x^{*}(q ; \beta)}{\partial q}\right] \\
=E_{\beta}\left[\left[\tau-(1-\beta) \delta h^{\prime}\left(x^{*}(q ; \beta)\right)\right] \frac{d x^{*}(q ; \beta)}{d q}\right]=0
\end{gathered}
$$

where the last step was obtained by using (3).

As we consider a case where a uniform tax is applied, choosing the optimal tax involves a trade-off between helping consumers with a severe self-control problem, whilst causing a distortion for those who are rational. From (4), the second-best optimal tax is given by

$$
\tau^{o}=\delta E_{\beta}\left[(1-\beta) h^{\prime}\left(x^{*}(q ; \beta)\right)\right]+\frac{\delta \operatorname{Cov}_{\beta}\left[(1-\beta) h^{\prime}\left(x^{*}(q ; \beta)\right), \frac{\partial x^{*}(q ; \beta)}{\partial q}\right]}{E_{\beta}\left[\frac{\partial x^{*}(q ; \beta)}{\partial q}\right]} .
$$

It should be noted that the socially optimal tax rate is independent of the way in which tax revenue is distributed back to consumers, that is, of the form of the function $S(\tau, \beta)$. Therefore, in both of the cases considered below - that is, regardless of whether sin taxes have redistributive effects or not - the socially optimal tax rate is given by (5).

In order to get clearer results in the current and the next section, we make the following assumption about the functional forms of $v(x)$ and $h(x)$ :

$$
\text { Assumption } 1 \quad \text { (i) } v^{\prime \prime \prime}(x) \geq 0 \text { and (ii) }-2 \leq \frac{h^{\prime \prime \prime}(x) h^{\prime}(x)}{\left[h^{\prime \prime}(x)\right]^{2}} \leq 1 \text {. }
$$

Assumption 1 is satisfied for commonly used functional forms, for example when $v$ is of the CRRA or CARA-variety ${ }^{13}$ or quadratic, and when the harm function is linear ${ }^{14}$, quadratic, exponential or $h(x)=x^{s}$ where $s \geq 4 / 3$.

We can now proceed to analyse the socially optimal tax rate in (5). The first term, $\delta E\left[(1-\beta) h^{\prime}\left(x^{*}\right)\right]$, is the average distortion caused by self-control problems in the economy. It can be shown that the second term in (5) is positive given Assumption 1. We can therefore state the following proposition:

Proposition 1 The socially optimal sin tax is higher than the average distortion caused by self-control problems, that is, $\tau^{o}>\delta E_{\beta}\left[(1-\beta) h^{\prime}\left(x^{*}(q ; \beta)\right)\right]$.

Proof. See the appendix.

It is shown in the appendix that a sufficient condition for Proposition 1 is that $\frac{\partial^{2} x^{*}(q ; \beta)}{\partial q \partial \beta}>$ 0 , which holds given Assumption 1. The condition $\frac{\partial^{2} x^{*}(q ; \beta)}{\partial q \partial \beta}>0$ has a very intuitive explanation: it implies that taxation has a larger impact on irrational consumers with a very high

\footnotetext{
${ }^{13}$ Kimball (1990) provides an economic interpretation of the condition $v^{\prime \prime \prime}>0$, albeit from a context that is rather different from ours: $v^{\prime \prime \prime}>0$ is associated with the concept of prudence, and implies that precautionary savings of risk averse individuals increase with increased uncertainty.

${ }^{14}$ Note that when the harm function is linear, part (i) of Assumption 1 has to hold as a strict inequality.
} 
level of consumption $(\beta \approx 0)$ than on rational consumers with a moderate level of consumption $(\beta \approx 1)$. The benefit of a high sin tax for consumers with a severe self-control problem thus exceeds the (negative) impact on the utility of (close to) rational individuals, and the socially optimal sin tax therefore exceeds the average distortion.

\section{Political equilibrium}

From the point of view of the consumer, the problem is that he would like to consume less in the future, but repeatedly fails to do so due to self-control problems. We assume throughout the analysis that consumers are sophisticated - that is, they are completely aware of their selfcontrol problem ${ }^{15}$. However, market-based mechanisms for correcting the distortion caused by time-inconsistent preferences are likely to be ineffective (see Köszegi (2005)): even though both consumers and firms would have the incentive, ex ante, to sign contracts that implement the optimal level of consumption, in a competitive market consumers cannot be prevented from purchasing from other firms ex post. Consumption of harmful goods is therefore as if only a spot market was available (that is, suboptimally high). To the extent that laws on commodity taxation cannot be changed each period, sophisticated consumers might thus value sin taxes as a way of committing to a lower level of consumption in the future.

In this section we analyse the level of taxes that will emerge in a political equilibrium and compare the equilibrium tax rate with the social optimum. In each case considered below, we assume that consumers vote over a sin tax to be implemented in all subsequent periods, starting from the period following the vote ${ }^{16}$. As the utility from all subsequent periods is discounted exponentially, the individual's policy preference function is given by his indirect long-run utility function, $V\left(q ; \beta_{i}\right)=v\left(x^{*}\left(q ; \beta_{i}\right)\right)-\delta h\left(x^{*}\left(q ; \beta_{i}\right)\right)+z$ : the individual's preferred tax rate will be the one that maximises his long-run utility, taking into account the fact that actual consumption decisions will be distorted in the absence of a sin tax.

Finally, we assume that the outcome of the vote is determined by direct majority rule ${ }^{17}$.

\footnotetext{
${ }^{15}$ The concepts of sophistication and naivete (complete unawareness of ones' self-control problem), were discussed already by Strotz (1955-6) and Pollak (1968) and have been recently analysed in numerous papers see for example O'Donoghue and Rabin (1999) for an analysis of the implications of both sophistication and naivete, and O'Donoghue and Rabin (2001) for a model that introduces a formalisation of the intermediate case of partial naivete. Since there are no intertemporal linkages in the marginal benefits and costs of consumption in our model, consumption decisions (in the absence of commitment) would be the same for naifs and sophisticates. However, voting decisions depend on whether the individual is aware of his self-control problem: (partially) naive individuals would vote for a lower tax than sophisticated individuals.

${ }^{16}$ If consumers were to vote on taxes only for this period, all consumers would vote for zero taxes; and if they were to vote on taxes to be implemented forever but including the current period, they would vote for a lower level of taxes than implied by the analysis below (the socially optimal level of taxes would also be lower; see Gruber and Köszegi $(2004,1967))$.

${ }^{17}$ The same results hold if there is a representative democracy with two-party electoral competition, the parties can fully commit to a tax policy and care only about their chances of being elected (and do not have preferences over the level of taxes themselves) - this would be a simple case of Downsian electoral competition (Downs (1957); see also Persson and Tabellini (2000)).
} 


\subsection{Benchmark: sin taxes have no redistributive effects}

Even though the social optimum is unaffected by the way in which tax revenue is distributed back to consumers, consumers clearly will not be indifferent about the subsidies that they receive. The shape of the function $S(\tau, \beta)$ thus has an effect on the political equilibrium. Consider first the case where the tax has no redistributive effects ${ }^{18}$, namely $S(\tau, \beta)=\tau x^{*}(q ; \beta) .{ }^{19}$ The long-run indirect utility function of individual $i$ and therefore the policy preference function of individual $i$ is then given by

$$
\begin{aligned}
V\left(q ; \beta_{i}\right) & =v\left(x^{*}\left(q ; \beta_{i}\right)\right)-\delta h\left(x^{*}\left(q ; \beta_{i}\right)\right)-(1+\tau) x^{*}\left(q ; \beta_{i}\right)+\tau x^{*}\left(q ; \beta_{i}\right)+B \\
& =v\left(x^{*}\left(q ; \beta_{i}\right)\right)-\delta h\left(x^{*}\left(q ; \beta_{i}\right)\right)-x^{*}\left(q ; \beta_{i}\right)+B .
\end{aligned}
$$

where $x^{*}$ again satisfies (3).

\subsubsection{The case of moderately harmful consumption}

In the case where sin taxes have no redistributive effects, the comparison between the equilibrium and the social optimum turns out to depend on the extent of harm from consumption. Let us first analyse the political equilibrium in the case where current consumption causes harm in the future, but the optimal (rational) level of consumption is nevertheless positive at zero taxes, that is $v^{\prime}(0)-\delta h^{\prime}(0)-1>0$. Using similar steps as in the previous section, the first-order condition is given by

$$
\frac{\partial V(q ; \beta)}{\partial q}=\left[\tau-(1-\beta) \delta h^{\prime}\left(x^{*}(q ; \beta)\right)\right] \frac{\partial x^{*}(q ; \beta)}{\partial q}
$$

and each individual's preferred tax rate is given by

$$
\tau^{*}(\beta)=(1-\beta) \delta h^{\prime}\left(x^{*}(q ; \beta)\right) .
$$

The policy preference function (6) is single-peaked ${ }^{20}$, and a majority voting equilibrium therefore exists and the tax rate preferred by the voter with the median most preferred level of taxes is chosen in equilibrium. Further, policy preferences are clearly monotonic in $\beta$ : in the absence of redistribution, each individual prefers the tax rate that fully corrects the distortion in consumption. Since the distortion term $(1-\beta) \delta h^{\prime}\left(x^{*}(q ; \beta)\right)$ is decreasing in $\beta$, the individually preferred tax rate is monotonically increasing in the level of self-control problems. Given this monotonicity, the tax rate chosen in a majority voting equilibrium is

\footnotetext{
${ }^{18}$ In the present setting, it would also be possible to set individual-specific taxes. However, this case would not be very interesting, as there would then be no interpersonal trade-offs to be settled. The case of individualspecific transfers is also rather unrealistic, but it is useful for illustrating some of the key mechanisms in this paper, and serves as a benchmark for the more realistic case where sin taxes have redistributive effects.

${ }^{19}$ It is important to note that $S(\tau, \beta)$ is a lump-sum payment, and the consumer cannot change the subsidy by deviating from $x^{*}$.$$
20 \frac{d^{2} V\left(q, \beta_{i}\right)}{d q^{2}}=\left[v^{\prime \prime}\left(x^{*}\right)-\delta \gamma h^{\prime \prime}\left(x^{*}\right)\right]\left(\frac{d x^{*}}{d q}\right)^{2}-\left[v^{\prime}\left(x^{*}\right)-\delta \gamma h^{\prime}\left(x^{*}\right)-1\right] \frac{d^{2} x^{*}}{d q^{2}}<0 .
$$ 
given by

$$
\tau^{*}=\left(1-\beta_{\text {med }}\right) \delta h^{\prime}\left(x^{*}\left(q ; \beta_{\text {med }}\right)\right) .
$$

We are now in a position to compare the tax rate chosen in political equilibrium, $\tau^{*}$, to the socially optimal tax rate $\tau^{o}$. Let us first examine a simple case, where the harm function is linear, namely $h(x)=g x$. In this case $\tau^{*}=\delta g\left(1-\beta_{\text {med }}\right)$. On the other hand, equation (5) implies that $\tau^{o}=\delta g(1-E[\beta]+\kappa)$, where $\kappa \equiv \operatorname{Cov}\left[(1-\beta), \frac{\partial x^{*}(q ; \beta)}{\partial q}\right] / E_{\beta}\left[\frac{\partial x^{*}(q ; \beta)}{\partial q}\right]>0$. Then clearly $\tau^{*}<\tau^{o}$, as long as $E[\beta]<\beta_{\text {med }}+\kappa$. That is, the equilibrium tax rate is lower than the socially optimal rate, as long as there are enough relatively rational individuals (when the distribution of $\beta$ is not too much skewed to the right). In the appendix, we show that this result holds also for more general harm functions.

Proposition 2 Assume that sin taxes have no redistributive effects and the optimal level of consumption at zero taxes is positive. If the distribution of $\beta$ is not too much skewed to the right, the socially optimal tax rate is higher than the tax rate chosen in a majority voting equilibrium.

Proof. See the appendix.

The reader may worry that since the tax formulae in (5) and (9) are given only in implicit form, the result in Proposition 2 might only be related to tax rules, and not to actual tax levels. Limitations of this type are very common in the optimal taxation literature (see for example Gaube (2005)). However, using a Taylor-approximation of (7), we have further shown in the appendix that $\frac{d W(q)}{d q}-\frac{\partial V\left(q ; \beta_{\text {med }}\right)}{\partial q} \geq 0$ for all $q$, and therefore the result that $\tau^{o}>\tau^{*}$ is robust to this objection. ${ }^{21}$ This conclusion holds as long as the approximation used in the proof can be considered to be valid. Given that we are in the current subsection concerned with goods that are moderately harmful (and tax rates should therefore not be very high), the approximation is likely to be fairly innocuous.

The case of a symmetric distribution of $\beta$ is worth emphasising - in this case, intuition might suggest that the equilibrium and the socially optimal tax rates should coincide, but we have shown that the result $\tau^{o}>\tau^{*}$ nevertheless holds: there is a kind of bias in voting behaviour that tends to make the equilibrium tax rate too low.

In order to further clarify the intuition behind the result stated in Proposition 2, let us examine a specific example where there are three individuals with $\beta_{1}=0, \beta_{2}=\frac{1}{2}$ and $\beta_{3}=1$. Then $\beta_{\text {med }}=E[\beta]=\frac{1}{2}$. The tax rate chosen in political equilibrium, $\tau^{*}$ now equals the tax

${ }^{21}$ To show that $\frac{d W(q)}{d q}-\frac{\partial V\left(q ; \beta_{m e d}\right)}{\partial q}>0$ implies $q^{o}>q^{*}$, denote $\Delta(q) \equiv \frac{d W(q)}{d q}-\frac{\partial V\left(q ; \beta_{m e d}\right)}{\partial q}>0$ and $\widetilde{\Delta} \equiv$ $W(1)-V\left(1, \beta_{\text {med }}\right)$. Now $W(q)=V\left(q, \beta_{\text {med }}\right)+\int_{1}^{q} \Delta(\widehat{q}) d \widehat{q}+\widetilde{\Delta}$. The price level chosen in the political equilibrium is $q^{*}=\arg \max _{q} V\left(q, \beta_{\text {med }}\right)$. Next we show that the socially optimal price level $q^{o}=\arg \max W(q)>q^{*}$. (i) Assume by contrast that $q^{o}=\widetilde{q}<q^{*}$. Now $W(\widetilde{q})=W\left(q^{*}\right)-\left[V\left(q^{*}, \beta_{\text {med }}\right)-V\left(\widetilde{q}, \beta_{\text {med }}\right)\right]-\int_{\widetilde{q}}^{q^{*}} \Delta(\widehat{q}) d \widehat{q}<$ $W\left(q^{*}\right)$. Thus $\widetilde{q}$ cannot be optimal, a contradiction. (ii) $W^{\prime}\left(q^{*}\right)=\frac{\partial V\left(q^{*}, \beta_{m e d}\right)}{\partial q}+\Delta\left(q^{*}\right)>0$, where the inequality follows since $\frac{\partial V\left(q^{*}, \beta_{m e d}\right)}{\partial q}=0$ and $\Delta\left(q^{*}\right)>0$. Thus we can conclude that $q^{o}>q^{*}$. Notice that this proof applies even if $W(q)$ and $V(q)$ are multi-peaked. 
rate preferred by individual 2 . The tax rate $\tau^{*}$ is socially optimal if and only if

$$
\frac{d W\left(q^{*}\right)}{d q} \equiv \frac{\partial V\left(q^{*} ; \beta_{1}\right)}{\partial q}+\frac{\partial V\left(q^{*} ; \beta_{2}\right)}{\partial q}+\frac{\partial V\left(q^{*} ; \beta_{3}\right)}{\partial q}=0
$$

Because $\frac{d V\left(q^{*} ; \beta_{2}\right)}{d q}=0$, this condition can be written as

$$
\frac{\partial V\left(q^{*} ; \beta_{1}\right)}{\partial q}=-\frac{\partial V\left(q^{*} ; \beta_{3}\right)}{\partial q}
$$

Typically, the condition (10) does not hold in equilibrium. As an example, assume that $v(x)=\frac{\varepsilon}{\varepsilon-1} x^{\frac{\varepsilon-1}{\varepsilon}}$ and $h(x)=g x$ and the demand function is therefore $x^{*}(q ; \beta)=(q+\beta \delta)^{-\varepsilon}$. With these functional forms, the tax rate chosen in political equilibrium is given by

$$
\frac{\partial V\left(q^{*} ; \beta_{2}\right)}{\partial q}=0 \Leftrightarrow \tau^{*}=\left(1-\beta_{2}\right) \delta g=\frac{1}{2} \delta g
$$

We then have that

$$
\begin{aligned}
& \frac{\partial V\left(q^{*} ; \beta_{1}\right)}{\partial q}=\left[\tau^{*}-\left(1-\beta_{1}\right) \delta g\right] \frac{\partial x^{*}\left(q^{*}, \beta_{1}\right)}{\partial q}=\frac{1}{2} \delta g \varepsilon\left(1+\frac{1}{2} \delta\right)^{-(\varepsilon+1)}>0 \\
& \frac{\partial V\left(q^{*} ; \beta_{3}\right)}{\partial q}=\left[\tau^{*}-\left(1-\beta_{3}\right) \delta g\right] \frac{\partial x^{*}\left(q^{*}, \beta_{3}\right)}{\partial q}=-\frac{1}{2} \delta g \varepsilon\left(1+\frac{3}{2} \delta\right)^{-(\varepsilon+1)}<0
\end{aligned}
$$

For individual 1 with a very severe self-control problem, the best outcome would be to have $\tau_{1}^{*}=\delta g$; the preferred outcome of the fully rational individual 3 would be to have no taxes, $\tau_{3}^{*}=0$. In other words, the equilibrium tax rate is too low from the point of view of consumer 1 and too high from the point of view of consumer 3. Further, the absolute value of the difference between the equilibrium tax rate and each individual's preferred tax rate is the same for both individuals 1 and $3:^{22}$

$$
\left|\tau^{*}-\tau_{i}^{*}\right|=\left|\tau^{*}-\left(1-\beta_{i}\right) \delta g\right|=\frac{1}{2} \delta g \varepsilon, i=1,3 .
$$

Nevertheless, we have that

$$
\frac{\partial x^{*}\left(q^{*}, \beta_{1}\right)}{\partial q}=\left(1+\frac{1}{2} \delta g\right)^{-(\varepsilon+1)}>\left(1+\frac{3}{2} \delta g\right)^{-(\varepsilon+1)}=\frac{\partial x^{*}\left(q^{*}, \beta_{3}\right)}{\partial q} .
$$

In other words, a change in the tax rate affects the consumption decision of individual 1 more than it affects the consumption choice of individual 3. The result is very intuitive: the rational individual has a low level of consumption, and therefore increasing the sin tax cannot have a very large effect on his consumption level (in absolute terms). On the other hand, the individual with a severe self-control problem has a high level of consumption, and a tax

\footnotetext{
${ }^{22}$ This equality is caused by the linearity of $h(x)$.
} 
increase has a larger effect on his level of consumption. Therefore we have that

$$
\frac{\partial V\left(q^{*} ; \beta_{1}\right)}{\partial q}>-\frac{\partial V\left(q^{*} ; \beta_{3}\right)}{\partial q}
$$

and thus

$$
\frac{d W\left(q^{*}\right)}{d q}>0
$$

This example confirms our intuition that if we take the political equilibrium as a starting point and increase the tax rate slightly, the self-control benefit gained by the individual with a severe self-control problem is higher than the loss experienced by close to rational individuals. However, the median voter does not take this asymmetric effect into account. Therefore even if the distribution of self-control problems is symmetric, the equilibrium tax rate is below the socially optimal level.

\subsubsection{The case of very harmful consumption}

Consider next the case where consumption of commodity $x$ is so harmful that the optimal (rational) level of consumption is zero even at zero taxes, that is, $v^{\prime}(0)-\delta h^{\prime}(0)-1 \leq 0$. It is then immediately clear that, in the social optimum, no one should consume $x$. The (minimum) tax rate $\left(\tau^{o}\right)$ needed to implement the social optimum is such that even the least rational consumer abstains, and it is given by

$$
\tau^{o}=v^{\prime}(0)-\beta_{L} \delta h^{\prime}(0)-1
$$

It is easy to see that the socially optimal sin tax is in this case also a majority voting equilibrium for any distribution of $\beta$ and for all functional forms $v(x)$ and $h(x)$ :

Proposition 3 Assume that sin taxes have no redistributive effects and the optimal level of consumption at zero taxes is zero. The socially optimal tax is then a majority voting equilibrium.

Proof. Individuals with $\beta_{i}=\beta_{L}$ strictly prefer $\tau^{o}$ to any other tax rate. All individuals with $\beta_{i}>\beta_{L}$ strictly prefer $\tau^{o}$ to any tax rate below $\hat{\tau}=v^{\prime}(0)-\beta_{i} \delta h^{\prime}(0)-1$ and are indifferent between $\tau^{o}$ and any tax rate $\tau \subseteq\left[\hat{\tau}, \tau^{o}\right]$.

That is, when it is optimal to abstain from the consumption of good $x$ even in the absence of any taxation, all consumers prefer a tax policy that will help them to achieve a zero level of consumption. The socially optimal tax achieves this outcome and will therefore be a majority voting equilibrium. However, we show in section 4.2.2 that this result changes when we take into account the redistributive effects of sin taxes. 


\subsection{Accounting for the redistributive effects of sin taxes}

Let us next analyse the more realistic case where the social planner does not have information on individual consumption levels, so that the subsidy paid to each consumer cannot be conditioned on individual consumption. We therefore assume from now on that all consumers receive a lump-sum transfer of equal size, and this subsidy is given by $S(q ; \beta)=S(q)=$ $\tau E_{\beta}[x(q ; \beta)]$. The consumers' policy preference function is then given by

$$
\tilde{V}\left(q ; \beta_{i}\right)=v\left(x^{*}\left(q ; \beta_{i}\right)\right)-\delta h\left(x^{*}\left(q ; \beta_{i}\right)\right)-q x^{*}+\tau E_{\beta}\left[x^{*}(q ; \beta)\right]+B .
$$

\subsubsection{The case of moderately harmful consumption}

Consider again first the case where current consumption causes harm in the future, but the optimal (rational) level of consumption is nevertheless positive at zero taxes, that is, $v^{\prime}(0)-\delta h^{\prime}(0)-1>0$. The first-order condition that determines voting behaviour of individual $i$ is now given by

$$
\begin{aligned}
\frac{\partial \tilde{V}\left(q ; \beta_{i}\right)}{\partial q}= & -\left(1-\beta_{i}\right) \delta h^{\prime}\left(x^{*}\left(q ; \beta_{i}\right)\right) \frac{\partial x^{*}\left(q ; \beta_{i}\right)}{\partial q} \\
& -x^{*}\left(q ; \beta_{i}\right)+E_{\beta}\left[x^{*}(q ; \beta)\right]+\tau E_{\beta}\left[\frac{\partial x^{*}(q ; \beta)}{\partial q}\right] .
\end{aligned}
$$

In the case where taxation had no redistributive effects it was easy to see that the individual's preferred tax rate was monotonic in the level of self-control problems and a majority voting equilibrium was therefore guaranteed to exists. However, as noted in the introduction, in the case where sin taxes have redistributive effects there are two forces at play: on the one hand, a person with a high level of self-control problems will prefer a high tax in order to alleviate the distortion in his consumption decision. The corrective effect of taxation is identical to the case where sin taxes have no redistributive effects, and is given by the first term in (12). On the other hand, however, a high tax will also imply a transfer of income towards individuals with a relatively low level of consumption: this redistributive effect of taxation is captured by the remaining terms in (12). Because of these two opposite effects, policy preferences may not be well-behaved, and the existence of a majority voting equilibrium is therefore not self-evident in this case.

A median voter equilibrium exists if policy preferences satisfy the Gans-Smart single crossing property (Gans and Smart 1996). Gans and Smart show that when underlying preferences are defined over a two-dimensional real choice variable but attention can be restricted to a one-dimensional choice due to production or budget constraints (in our case due to the consumer's budget constraint), then single-crossing in the Spence-Mirrlees sense implies single-crossing in the Gans-Smart sense.

We therefore use the Spence-Mirrlees single-crossing condition to analyse the existence of 
a median voter equilibrium. The voters' preferences satisfy the Spence-Mirrlees condition if voters' marginal rates of substitution between $z$ and $q,-\frac{\tilde{V}_{q}}{\tilde{V}_{z}}$, are globally monotonic in $\beta$. In our simple case of quasilinear preferences $\left(\tilde{V}_{z}=1\right)$, the condition reduces to $\frac{\partial \tilde{V}\left(q ; \beta_{i}\right)}{\partial q}$ being monotonic in $\beta$.

In the appendix, we prove that $\frac{\partial \tilde{V}\left(q ; \beta_{i}\right)}{\partial q \partial \beta} \leq 0$, and we can therefore state the following proposition:

Proposition 4 Assume that revenue from sin taxes is distributed equally among consumers. A majority voting equilibrium exists and the equilibrium sin tax is given by the tax rate preferred by the consumer with the median level of self-control problems.

Proof. See the appendix.

The result $\frac{\partial \tilde{V}\left(q ; \beta_{i}\right)}{\partial q \partial \beta} \leq 0$ implies that an individuals' most preferred tax rate is again monotonically increasing in the level of self-control problems. To gain some intuition on why this holds also when the redistributive effects of sin taxes are taken into account, using equations (16) and (23) (see the appendix), the corrective term in (12) can be written as

$$
-\left(1-\beta_{i}\right) \delta h^{\prime}\left(x^{*}\left(q ; \beta_{i}\right)\right) \frac{\partial x^{*}\left(q ; \beta_{i}\right)}{\partial q}=x^{*}\left(q ; \beta_{i}\right)-x^{*}(q ; 1)+\Phi\left(q, \beta_{i}\right),
$$

where $\Phi\left(q, \beta_{i}\right)=\int_{\beta_{i}}^{\beta_{H}}(1-\hat{\beta}) \frac{\partial^{2} x(q ; \hat{\beta})}{\partial \widehat{\beta}^{2}} d \widehat{\beta}>0$ and $\Phi\left(q, \beta_{i}\right)$ is increasing in the level of selfcontrol problems (decreasing in $\beta$ ). As expected, the corrective effect of the tax is the larger, the more consumption $x^{*}\left(q ; \beta_{i}\right)$ differs from the quantity chosen by the rational consumer, $x^{*}(q ; 1)$. Further, the magnitude of the corrective effect exceeds the difference $x^{*}\left(q ; \beta_{i}\right)-$ $x^{*}(q ; 1)$. Importantly, the difference between the corrective effect and the monetary cost of the tax is increasing in the level of self-control problems: therefore, relatively irrational individuals prefer a higher tax rate than those who are relatively rational.

To illustrate, consider again the example where $v(x)=\frac{\varepsilon}{\varepsilon-1} x^{\frac{\varepsilon-1}{\varepsilon}}$ and $h(x)=g x$. With these functional forms, the self-control benefit from taxation can be expressed as

$$
-\left(1-\beta_{i}\right) \delta h^{\prime}\left(x^{*}\left(q ; \beta_{i}\right)\right) \frac{\partial x^{*}\left(q ; \beta_{i}\right)}{\partial q}=\varepsilon(\delta g+q) x_{i}^{\frac{\varepsilon+1}{\varepsilon}}-\varepsilon x_{i} .
$$

It is easy to see from this expression that the self-control benefit increases more than linearly with the quantity consumed, which in turn is an increasing and convex function of self-control problems. Hence the self-control benefits increase more rapidly than monetary costs (which depend linearly on consumption), and the individuals' preferred tax rate is increasing in the level of self-control problems.

The specific functional forms used in the previous example serve to illustrate the mechanism behind Proposition 4. However, the property that self-control benefits increase more rapidly than monetary costs is more general, as Proposition 4 holds for all functional forms 
that satisfy Assumption 1. The intuition is apparent when we examine the three components that affect the magnitude of self-control benefits: Firstly, the harm function has been assumed to be either linear or convex. Secondly, the sensitivity of demand to tax changes increases with self-control problems. Finally, these two effects are multiplied by the level of self-control problems, $\left(1-\beta_{i}\right)$. Hence, these three forces reinforce each other, causing the self-control benefits to quite generally increase more than linearly in the level of consumption.

It is interesting to note that even in the present case where the optimal level of consumption in the absence of taxes is positive, there may be circumstances under which the redistributive motive for taxation implies that the median voter prefers not to consume in equilibrium, and will vote for the tax rate that maximises revenue. We have shown in the proof of Proposition 4, however, that single-crossing holds regardless of whether the median voter consumes the good in equilibrium or not. Therefore there cannot be situations where a coalition of near-rational users and highly irrational heavy-users vote for highest taxes, and are pitted against voters with an intermediate degree of rationality ${ }^{23}$.

Let us next turn to the comparison between the equilibrium and the optimum. Proposition 4 implies that the equilibrium tax rate is now given by

$$
\tau^{*}=\frac{\left(1-\beta_{\text {med }}\right) \delta h^{\prime}\left(x^{*}\left(q ; \beta_{\text {med }}\right)\right)\left|\frac{\partial x^{*}\left(q ; \beta_{\text {med }}\right)}{\partial q}\right|-x^{*}\left(q ; \beta_{\text {med }}\right)+E_{\beta}\left[x^{*}(q ; \beta)\right]}{E_{\beta}\left|\frac{\partial x^{*}(q ; \beta)}{\partial q}\right|} .
$$

The term $E_{\beta}\left[x^{*}(q ; \beta)\right]-x^{*}\left(q ; \beta_{\text {med }}\right)$ in the above formula captures the fact that if $x^{*}\left(q ; \beta_{\text {med }}\right)<$ $E_{\beta}\left[x^{*}(q ; \beta)\right]$, sin taxes imply a transfer of income towards the median voter. This will typically occur if the distribution of $\beta$ is skewed to the left so that $\beta_{\text {med }}>E[\beta]$ (though it can also occur in other cases, depending on the exact functional form of $x^{*}$ ). In such circumstances, the median voter then votes for a higher tax than he would in the absence of redistribution. Nevertheless, we can show that the equilibrium tax rate is again typically below the socially optimal level:

Proposition 5 Assume that revenue from sin taxes is distributed equally among consumers. If $(1-\beta) \frac{\partial^{2} x(q ; \beta)}{\partial \beta^{2}}$ is non-increasing in $\beta$ and the distribution of $\beta$ is not too much skewed to the right, the socially optimal tax rate is higher than the tax rate chosen in a majority voting equilibrium.

Proof. See the appendix.

\footnotetext{
${ }^{23}$ It appears that this property might be related to our assumption of quasilinear preferences, and the implied zero income elasticity of demand for good $x$. Whether more general assumptions about preferences can give rise to voting coalitions where highly irrational consumers and fully rational consumers vote for higher taxes than consumers with an intermediate level of rationality, is left as a question for further research. See Epple and Romano (1996) for an analysis - albeit in a very different context - where the preferred level of public expenditure and taxation is non-monotonic in consumer type (in their case income) when the income elasticity of demand exceeds the (absolute value of the) price elasticity.
} 
In the appendix, we show that if $(1-\beta) \frac{\partial^{2} x(q ; \beta)}{\partial \beta^{2}}$ is non-increasing in $\beta$, the derivative (12) is not only increasing, but also a convex function of the level of self-control problems. The result therefore again has a very intuitive explanation: the convexity of (12) implies that the marginal welfare benefit of high taxation for relatively irrational individuals is higher than the corresponding welfare loss for close to rational individuals. The condition that $(1-\beta) \frac{\partial^{2} x(q ; \beta)}{\partial \beta^{2}}$ should be non-increasing in $\beta$ again holds for many commonly used functional forms, for example when $v$ is of the CRRA or CARA-variety or quadratic, and when the harm function is linear or $h(x)=x^{s}$ where $s \geq 2$.

Further, in order to interpret the condition that $(1-\beta) \frac{\partial^{2} x(q ; \beta)}{\partial \beta^{2}}$ should be non-increasing in $\beta$, we show in the appendix that this holds (approximately) if a price change affects the health of irrational consumers (heavy users) more than the health of rational consumers. This holds given Assumption 1.

Proposition 5 shows that despite the fact that high sin taxes result in a transfer of income towards the median voter, the equilibrium tax rate is lower than the socially optimal tax: the income transfer is not sufficient for the median voter to fully internalise the benefit that would accrue to highly irrational individuals, if the tax rate was increased.

For the case of moderately harmful consumption, therefore, our result is identical to the benchmark case where sin taxes have no redistributive effects. If harm from consumption is very low, this result is intuitive: in this case even rational consumers consume a lot of the good in question, and the concern for alleviating distortions in consumption is stronger than the motive for redistributing tax revenue. This case therefore resembles the case where taxation has no redistributive effects, discussed above, and the results are the same for the two cases - equilibrium taxes tend to be too low.

However, in contrast to the case where sin taxes have no redistributive effects, it is important to note that the conclusion that equilibrium taxes tend to be too low holds in the present case for all levels of harm. We turn next to the interesting case of very harmful consumption.

\subsubsection{The case of very harmful consumption}

Consider again the case where consumption is so harmful that at zero taxes, the optimal choice is to abstain from consuming the commodity $x$. The (minimum) tax rate $\left(\tau^{o}\right)$ needed to implement the social optimum is then given by (11).

The condition for the result $\tau^{*}<\tau^{o}$ to hold in this case is especially mild, namely that $\beta_{\text {med }}$ does not coincide with the lowest level of $\beta$. Further it is important to note that this result does not depend on Assumption 1, but holds for any functional forms of $v(x)$ and $h(x)$ :

Proposition 6 Assume that revenue from sin taxes is distributed equally among consumers and consumption is so harmful that the optimal level of consumption at zero taxes is zero. 
Then, for any distribution of self-control problems where $\beta_{\text {med }}>\beta_{L}$, the socially optimal tax rate is higher than the tax rate chosen in a majority voting equilibrium.

Proof. Since no agent consumes at $\tau=\tau^{o}$, no tax revenues are collected in the social optimum. Suppose that, starting from $\tau=\tau^{o}$, the tax rate is lowered by a small amount $d \tau$. Then the least rational consumers $\left(\beta_{L}\right)$, who were just indifferent between consuming and not consuming, are triggered to consume a small amount

$$
x\left(\beta_{L} ; \tau^{o}-d \tau\right)=-\frac{d \tau}{v^{\prime \prime}(0)+\beta_{L} h^{\prime \prime}(0)}>0 .
$$

Also, tax revenues increase from zero to $-\frac{\tau^{o} d \tau}{v^{\prime \prime}(0)+\beta_{L} h^{\prime \prime}(0)}$. Consumers other than type $\beta_{L}$ still consume no $x$, and the welfare of this majority group increases, due to transfers from type $\beta_{L}$. The redistributive motive for taxation then implies that the level of taxes that eliminates all consumption cannot arise as a political equilibrium.

\section{Extension: third-best $\sin$ taxes}

Our analysis can be easily generalised to the case where sin taxes not only have a corrective role, but the government also has a revenue raising objective. Total social welfare is now taken to be the sum of the utility from private consumption and from public funds. Let $\mu$ denote the marginal social value of revenue from the sin tax (or the marginal cost of raising revenue from other tax bases) ${ }^{24}$. Previously, we have had that $\mu=1$, since all tax revenue has been returned to consumers and we have assumed that the marginal utility of (private) income is 1 . However, now we allow for the possibility that part of the tax revenue is used for public goods and services. In the general case where the marginal value of public consumption differs from the marginal value of private consumption, we have that $\mu \neq 1$.

Social welfare is now given by

$$
W(q, \mu)=E_{\beta}[V(q, \mu ; \beta)]=E_{\beta}\left[v\left(x^{*}(q ; \beta)\right)-\delta h\left(x^{*}(q ; \beta)\right)-(1+(1-\mu) \tau) x^{*}(q ; \beta)\right]+B
$$

This extension does not affect the comparison between the equilibrium and the socially optimal tax rate ${ }^{25}$. To see this, note that the individual's policy preference function is now given by

$$
\tilde{V}\left(q ; \beta_{i}\right)=v\left(x^{*}\left(q ; \beta_{i}\right)\right)-\delta h\left(x^{*}\left(q ; \beta_{i}\right)\right)-q x^{*}+\mu \tau E_{\beta}\left[x^{*}(q ; \beta)\right]+B
$$

\footnotetext{
${ }^{24}$ For simplicity, we consider a partial equilibrium set-up where demands for other goods are assumed to be independent of the demand for the good under consideration and consequently, other tax bases are unaffected by the taxes in question. It is therefore also natural to assume that $\mu$ is constant with respect to $\tau$.

${ }^{25}$ This holds as long as we make the conventional assumption that consumers' and the social planner's valuations of public funds are identical. See Pirttilä and Tenhunen (2007) for an analysis where those valuations may differ.
} 
and its derivative is

$$
\begin{aligned}
\frac{\partial \tilde{V}\left(q ; \beta_{i}\right)}{\partial q}= & -\left(1-\beta_{i}\right) \delta h^{\prime}\left(x^{*}\left(q ; \beta_{i}\right)\right) \frac{\partial x^{*}\left(q ; \beta_{i}\right)}{\partial q} \\
& -x^{*}\left(q ; \beta_{i}\right)+\mu\left\{E_{\beta}\left[x^{*}(q ; \beta)\right]+\tau E_{\beta}\left[\frac{\partial x^{*}(q ; \beta)}{\partial q}\right]\right\} .
\end{aligned}
$$

It is important to note that the part of this derivative that depends on $\beta$ is independent of $\mu$, and therefore $\frac{\partial \tilde{V}\left(q ; \beta_{i}\right)}{\partial q}$ is still increasing and convex in the level of self-control problems, as above. The equilibrium tax rate is therefore typically lower than the socially optimal tax also in this third-best setting. We can therefore state the following proposition:

Proposition 7 Assume that sin taxes are used for revenue raising purposes. If $(1-\beta) \frac{\partial^{2} x(q ; \beta)}{\partial \beta^{2}}$ is non-increasing in $\beta$ and the distribution of $\beta$ is not too much skewed to the right, the thirdbest optimal sin tax is higher than the tax rate chosen in a majority voting equilibrium.

However, even though the qualitative comparison between the socially optimal and the equilibrium tax rate is not altered, incorporating a revenue raising objective into the social welfare function does affect the actual levels of taxes. Consider the socially optimal tax rate. The third-best optimal sin tax is given by

$$
\tau^{T B}=\frac{1}{\mu} \frac{E_{\beta}\left[(1-\beta) \delta h^{\prime}\left(x^{*}(q ; \beta)\right) \frac{\partial x^{*}(q ; \beta)}{\partial q}\right]}{E_{\beta}\left[\frac{\partial x^{*}(q ; \beta)}{\partial q}\right]}+\frac{(1-\mu)}{\mu} \frac{E_{\beta}\left[x^{*}(q ; \beta)\right]}{E_{\beta}\left[\frac{\partial x^{*}(q ; \beta)}{\partial q}\right]} .
$$

The first term in (14) reflects the corrective role of sin taxes, whereas the second term reflects the standard public finance argument for taxation. The corrective part enters the optimal tax formula additively, in accordance with the additivity principle familiar from the context of environmental taxation (Sandmo 1975). If $\mu=1$, we get the formula in (5). Typically, however, if other taxes are distortionary, $\mu>1$ and the public finance term is positive. The direct effect of public finance considerations is therefore to increase the socially optimal sin tax.

On the other hand, for $\mu>1$ the corrective part of the tax is scaled down. The fact that the corrective part is lower than in the case where taxation only has a corrective role is analogous to the principle of incomplete internalisation of environmental externalities in the presence of distortive taxation (Bovenberg and de Mooij 1994). This feature can be explained by the fact that the marginal costs of harm reduction increase with the marginal cost of public funds.

The overall effect of public finance considerations on the magnitude of the optimal sin tax is in general ambiguous. However, it is self-evident that in the case where $\mu>1$, that is when tax revenue has a higher weight in the social welfare function than private consumption, the 
third-best optimal sin tax is higher than the tax rate given in (5) if and only if (5) is on an upward-sloping segment of the Laffer curve.

In some cases, for example if a part of tax revenue is wasted (for example due to administrative costs) a case where $\mu<1$ may be relevant. In this case, the second term in (14) is negative whereas the first part is scaled up. Again, it is worth emphasising that our result regarding the comparison between $\tau^{*}$ and $\tau^{o}$ does not depend on the value of $\mu$. Therefore, the result that the optimal tax rate exceeds the equilibrium level of taxes holds even in the case where part of tax revenue is wasted.

\section{Conclusions}

We have shown that optimal sin taxes will typically exceed the average distortion caused by self-control problems in the economy: this result arises due to the asymmetric effects of sin taxes on the welfare of those with severe self-control problems on the one hand, and on (close to) rational individuals on the other hand. As the median voter does not take such asymmetries into account, the sin taxes chosen in a majority voting equilibrium are in most cases below the socially optimal level.

The view that emerges from previous empirical literature seems to be that for example excise duties on cigarettes are in most countries very high compared to the external costs of smoking. However, the present analysis provides a theoretical argument that suggests that such taxes may nevertheless be too low from a social point of view.

The analysis also suggests a reason for why it may be optimal to impose quantity restrictions on the consumption of certain highly harmful substances (such as illicit drugs), rather than using price instruments alone: if we were to rely solely on tax policy to regulate the consumption of such substances, the optimal outcome may not be reached.

It should be noted that throughout the analysis, we have assumed that individuals are sophisticated - that is, they are fully aware of their self-control problem. Individuals thus value sin taxes as a self-control device, and vote for positive taxes. However, if some individuals are partially naive, their preferred tax rate will be lower than the level indicated by our results

- indeed, fully naive individuals would vote for a zero tax, as they are fully unaware of their self-control problem. In the case where some individuals are either partially or fully naive, therefore, the problem of sub-optimally low equilibrium taxes would be exacerbated.

\section{Appendix}

\section{Preliminaries}

The following derivatives are used a number of times in the analysis: 


$$
\begin{aligned}
& \frac{\partial x^{*}(q, \beta)}{\partial \beta}=\frac{\delta h^{\prime}\left(x^{*}\right)}{v^{\prime \prime}\left(x^{*}\right)-\beta \delta h^{\prime \prime}\left(x^{*}\right)}<0 \\
& \frac{\partial x^{*}(q, \beta)}{\partial q}=\frac{1}{v^{\prime \prime}\left(x^{*}\right)-\beta \delta h^{\prime \prime}\left(x^{*}\right)}<0 .
\end{aligned}
$$

Given these results, the corrective effect of taxation can be written as

$$
-\left(1-\beta_{i}\right) \delta h^{\prime}\left(x^{*}\left(q ; \beta_{i}\right)\right) \frac{\partial x^{*}\left(q ; \beta_{i}\right)}{\partial q}=\left(1-\beta_{i}\right) \frac{\partial x(q ; \beta)}{\partial \beta} .
$$

\section{Proof of Proposition 1}

Since $E_{\beta}\left[\frac{\partial x^{*}}{\partial q}\right]<0, \tau^{o}>\delta E_{\beta}\left[(1-\beta) h^{\prime}\left(x^{*}(q ; \beta)\right)\right]$ if $\operatorname{Cov}_{\beta}\left[(1-\beta) h^{\prime}\left(x^{*}\right), \frac{\partial x^{*}}{\partial q}\right]<0$. When $h^{\prime \prime}(x) \geq 0,(1-\beta) h^{\prime}\left(x^{*}(q ; \beta)\right)$ is decreasing in $\beta$. Therefore, $\operatorname{Cov}_{\beta}\left[(1-\beta) h^{\prime}\left(x^{*}\right), \frac{d x^{*}}{d q}\right]<0$ if $\frac{\partial^{2} x^{*}(q ; \beta)}{\partial q \partial \beta}>0$. This derivative is given by

$$
\frac{\partial^{2} x^{*}(q ; \beta)}{\partial q \partial \beta}=\frac{-\left[v^{\prime \prime \prime}\left(x^{*}\right)-\beta \delta h^{\prime \prime \prime}\left(x^{*}\right)\right] \frac{\partial x^{*}}{\partial \beta}+\delta h^{\prime \prime}\left(x^{*}\right)}{\left[v^{\prime \prime}\left(x^{*}\right)-\beta \delta h^{\prime \prime}\left(x^{*}\right)\right]^{2}} .
$$

It can be shown that $\frac{\partial^{2} x^{*}(q ; \beta)}{\partial q \partial \beta}>0$ if (sufficient conditions) $v^{\prime \prime \prime}(x) \geq 0$ and

$$
\frac{h^{\prime \prime \prime}(x) h^{\prime}(x)}{\left[h^{\prime \prime}(x)\right]^{2}}<\frac{\beta \delta h^{\prime \prime}(x)-v^{\prime \prime}(x)}{\beta \delta h^{\prime \prime}(x)} .
$$

Clearly $\frac{\beta \delta h^{\prime \prime}(x)-v^{\prime \prime}(x)}{\beta \delta h^{\prime \prime}(x)}>1$. Thus the above condition is less demanding than

$$
\frac{h^{\prime \prime \prime}(x) h^{\prime}(x)}{\left[h^{\prime \prime}(x)\right]^{2}} \leq 1
$$

\section{Proof of Proposition 2}

In this proof, we first show that the right hand side of (5) is larger than the right hand side of (9). Secondly, we derive a condition that guarantees $\frac{d W(q)}{d q}-\frac{\partial V\left(q ; \beta_{\text {med }}\right)}{\partial q} \geq 0$. Thirdly, we interpret this condition, and use an approximation to show that it holds in our model.

i) In the text we show that the proposition holds for a linear $h(x)$. If $h(x)$ is not linear, then

$$
E_{\beta}\left[(1-\beta) h^{\prime}\left(x^{*}(q ; \beta)\right)\right] \neq\left(1-\beta_{\text {med }}\right) h^{\prime}\left(x^{*}\left(q ; \beta_{\text {med }}\right)\right)
$$

even if $\beta_{\text {med }}=E[\beta]$. In particular, if $\xi(\beta)=(1-\beta) h^{\prime}\left(x^{*}(q ; \beta)\right)$ is a convex function of $\beta$, then the Jensen inequality implies that

$$
E_{\beta}\left[(1-\beta) h^{\prime}\left(x^{*}(q ; \beta)\right)\right]>(1-E[\beta]) h^{\prime}\left(x^{*}(q ; E[\beta])\right)=\left(1-\beta_{\text {med }}\right) h^{\prime}\left(x^{*}\left(q ; \beta_{\text {med }}\right)\right) .
$$


We therefore need to show that $\frac{d^{2} \xi(\beta)}{d \beta^{2}}>0$. Now,

$$
\begin{gathered}
\frac{d \xi(\beta)}{d \beta}=-h^{\prime}\left(x^{*}\right)+(1-\beta) h^{\prime \prime}\left(x^{*}\right) \frac{d x^{*}}{d \beta} \\
\frac{d^{2} \xi(\beta)}{d \beta^{2}}=\left[(1-\beta) \frac{d^{2} x^{*}}{d \beta^{2}}-2 \frac{d x^{*}}{d \beta}\right] h^{\prime \prime}\left(x^{*}\right)+(1-\beta) h^{\prime \prime \prime}\left(x^{*}\right)\left(\frac{d x^{*}}{d \beta}\right)^{2} .
\end{gathered}
$$

It can be shown that $\frac{d^{2} \xi(\beta)}{d \beta^{2}}>0$ if $v^{\prime \prime \prime}(x) \geq 0$ and

$$
\frac{h^{\prime \prime \prime}(x) h^{\prime}(x)}{\left[h^{\prime \prime}(x)\right]^{2}}>-2 \frac{v^{\prime \prime}\left(x^{*}\right)-\beta \delta h^{\prime \prime}\left(x^{*}\right)}{v^{\prime \prime}\left(x^{*}\right)} \frac{\delta h^{\prime \prime}\left(x^{*}\right)-v^{\prime \prime}\left(x^{*}\right)}{\delta h^{\prime \prime}\left(x^{*}\right)} .
$$

Clearly,

$$
\frac{v^{\prime \prime}\left(x^{*}\right)-\beta \delta h^{\prime \prime}\left(x^{*}\right)}{v^{\prime \prime}\left(x^{*}\right)} \frac{\delta h^{\prime \prime}\left(x^{*}\right)-v^{\prime \prime}\left(x^{*}\right)}{\delta h^{\prime \prime}\left(x^{*}\right)}>1
$$

Thus (17) is less demanding than

$$
\frac{h^{\prime \prime \prime}(x) h^{\prime}(x)}{\left[h^{\prime \prime}(x)\right]^{2}} \geq-2
$$

Therefore $\xi(\beta)=(1-\beta) h^{\prime}\left(x^{*}\right)$ is a convex function of $\beta$ if $v^{\prime \prime \prime}(x) \geq 0$ and (18) holds (sufficient conditions). The condition (18) essentially states that $h^{\prime \prime \prime}(x)$ should not be too small, or equivalently, $h^{\prime}(x)$ should not be too concave: harm and therefore also self-control benefits from consumption depend on $h^{\prime}(x)$. Excessive concavity of $h^{\prime}(x)$ might thus offset the effect of increasing sensitivity to taxation as self-control problems get worse.

ii) Next, we show that $\frac{d W(q)}{d q}-\frac{\partial V\left(q ; \beta_{\text {med }}\right)}{\partial q} \geq 0$. For the remaining proofs, we find if useful to adopt the notation $\rho \equiv 1-\beta$, where $\rho$ measures the degree of self-control problems directly: for fully rational consumers $\rho=0$, and for fully myopic consumers $\rho=1$.

Using (16), $\frac{\partial V(q ; \rho)}{\partial q}$ can therefore be written as

$$
\begin{aligned}
\frac{\partial V(q ; \rho)}{\partial q} & =\left[\tau-\rho \delta h^{\prime}\left(x^{*}(q ; \rho)\right)\right] \frac{\partial x^{*}(q ; \rho)}{\partial q}=\tau \frac{\partial x^{*}(q ; \rho)}{\partial q}+\rho \frac{\partial x^{*}(q ; \rho)}{\partial \rho} \\
& =\frac{\partial V\left(q ; \rho_{L}\right)}{\partial q}+\int_{\rho_{L}}^{\rho}\left[\tau \frac{\partial^{2} x^{*}(q ; \widehat{\rho})}{\partial q \partial \hat{\rho}}+\widehat{\rho} \frac{\partial^{2} x^{*}(q ; \widehat{\rho})}{\partial \widehat{\rho}^{2}}+\frac{\partial x^{*}(q ; \widehat{\rho})}{\partial \widehat{\rho}}\right] d \widehat{\rho} .
\end{aligned}
$$

Adopting the notation

$$
\Psi(q, \rho)=\tau \frac{\partial^{2} x^{*}(q ; \rho)}{\partial q \partial \rho}+\rho \frac{\partial^{2} x^{*}(q ; \rho)}{\partial \rho^{2}}+\frac{\partial x^{*}(q ; \rho)}{\partial \rho}
$$


we know that $\frac{\partial V(q ; \rho)}{\partial q}$ is a convex function of $\rho$ if

$$
\frac{\partial \Psi(q, \rho)}{\partial \rho} \geq 0
$$

Given this convexity, $E_{\rho}\left[\frac{\partial V(q ; \rho)}{\partial q}\right]>\frac{\partial V(q ; E[\rho])}{\partial q}$ for all $q$. Also, since $\frac{\partial^{2} V(q ; \rho)}{\partial q \partial \rho}>0$, we can conclude that

$$
\frac{d W(q)}{d q}=E_{\rho}\left[\frac{\partial V(q ; \rho)}{\partial q}\right]>\frac{\partial V\left(q ; \rho_{m e d}\right)}{\partial q}
$$

if

$$
\rho_{\text {med }} \leq E[\rho]
$$

Therefore the equilibrium tax is lower than the socially optimal tax if (20) and (21) hold (sufficient conditions).

iii) Next, we proceed to interpreting condition (20). First note that (16) implies that

$$
\frac{\partial x^{*}(q ; \rho)}{\partial \rho}=-\delta \frac{\partial h\left(x^{*}(q ; \rho)\right)}{\partial q} .
$$

This is the effect of a price change on health. First-order Taylor series approximation with respect to $\rho$ and $q$ yields

$$
\frac{\partial x^{*}(q ; \rho)}{\partial \rho} \simeq \frac{\partial x^{*}(1 ; 0)}{\partial \rho}+\rho \frac{\partial^{2} x^{*}(q ; \rho)}{\partial \rho^{2}}+\tau \frac{\partial x^{*}(q ; \rho)}{\partial \rho \partial q}
$$

(note that the derivatives are evaluated at $(q, \rho)$ ). Solving the above expression for $\tau \frac{\partial x^{*}(q ; \rho)}{\partial \rho \partial q}$ and substituting into (19) yields

$$
\Psi(q, \rho) \simeq 2 \frac{\partial x^{*}(q ; \rho)}{\partial \rho}-\frac{\partial x^{*}(1 ; 0)}{\partial \rho} .
$$

The second term in this expression is a constant. Therefore, $\Psi(q, \rho)$ is increasing in $\rho$, if $\frac{\partial x^{*}(q ; \rho)}{\partial \rho}$ is increasing in $\rho$. Condition (20) therefore states that a price change affects the health of irrational consumers (heavy users) more than the health of rational consumers. Finally, we can check that this holds in our model:

$$
\frac{\partial\left(-\delta \frac{d h(x(q ; \rho))}{d q}\right)}{\partial \rho}=-\delta\left[h^{\prime}(x(q ; \rho)) \frac{\partial x(q ; \rho)}{\partial q} \frac{\partial x(q ; \rho)}{\partial \rho}+h^{\prime \prime}(x(q ; \rho)) \frac{\partial x^{2}(q ; \rho)}{\partial q \partial \rho}\right]>0
$$

The inequality follows from Assumption 1, which guarantees that $\frac{\partial x^{2}(q ; \rho)}{\partial q \partial \rho}>0$.

\section{Proof of Proposition 4}


To prove the existence of a majority voting equilibrium, we have to show that the SpenceMirrlees single-crossing condition is satisfied. Since we assume quasi-linear preferences this reduces to showing that $\frac{\partial \tilde{V}(q ; \rho)}{\partial q}$ is monotonic in $\rho$.

The effect of a marginal tax change on the welfare of type $\rho$ is now given by (12). Note that

$x(q ; \rho)=x\left(q ; \rho_{L}\right)+\int_{\rho_{L}}^{\rho} \frac{\partial x(q ; \widehat{\rho})}{\partial \widehat{\rho}} d \widehat{\rho}=x\left(q ; \rho_{L}\right)+\rho \frac{\partial x(q ; \rho)}{\partial \rho}-\rho_{L} \frac{\partial x\left(q ; \rho_{L}\right)}{\partial \rho}-\int_{\rho_{L}}^{\rho} \widehat{\rho} \frac{\partial^{2} x(q ; \widehat{\rho})}{\partial \widehat{\rho}^{2}} d \widehat{\rho}$.

Substituting (16) and (23) into (12) shows that

$$
\frac{\partial \tilde{V}(q ; \rho)}{\partial q}=\frac{\partial \tilde{V}\left(q ; \rho_{L}\right)}{\partial q}+\int_{\rho_{L}}^{\rho} \widehat{\rho} \frac{\partial^{2} x(q ; \widehat{\rho})}{\partial \widehat{\rho}^{2}} d \widehat{\rho}
$$

Differentiating with respect to $\rho$ yields

$$
\frac{\partial^{2} \tilde{V}(q ; \rho)}{\partial q \partial \rho}=\rho \frac{\partial^{2} x(q ; \rho)}{\partial \rho^{2}} \geq 0 .
$$

Notice that these results hold even when some individuals do not consume in equilibrium, that is, $x(q ; \rho)=0$ for $\rho \in\left[\rho_{L}, \widetilde{\rho}(q)\right]$, where $\widetilde{\rho}(q)$ is given by

$$
v^{\prime}(0)-(1-\widetilde{\rho}) \delta h^{\prime}(0)-q=0 \Leftrightarrow \widetilde{\rho}(q)=1-\frac{v^{\prime}(0)-q}{\delta h^{\prime}(0)} .
$$

Then

$$
\begin{aligned}
& \frac{\partial \tilde{V}(q ; \rho)}{\partial q}=\frac{d \tilde{V}\left(q ; \rho_{L}\right)}{d q}=E_{\rho}[x(q ; \beta)]+\tau E_{\rho}\left[\frac{\partial x(q ; \rho)}{\partial q}\right] \text { for } \rho \in\left[\rho_{L}, \widetilde{\rho}(q)\right] \\
& \frac{\partial \tilde{V}(q ; \rho)}{\partial q}=E_{\rho}[x(q ; \rho)]+\tau E_{\rho}\left[\frac{\partial x(q ; \rho)}{\partial q}\right]+\widetilde{\rho}(q) \frac{\partial x(q ; \tilde{\rho}(q))}{\partial \rho}+\int_{\widetilde{\rho}(q)}^{\rho} \widehat{\rho} \frac{\partial^{2} x(q ; \widehat{\rho})}{\partial \widehat{\rho}^{2}} d \widehat{\rho} \text { for } \rho>\widetilde{\rho}(q) .
\end{aligned}
$$

\section{Proof of Proposition 5}

From (24), $\frac{\partial \tilde{V}(q ; \rho)}{\partial q}$ is a convex function of $\rho$ if $\rho \frac{\partial^{2} x(q ; \rho)}{\partial \rho^{2}}$ is increasing in $\rho$. Given this convexity, the same argument as in the Proof of Proposition 2 shows that $\frac{d W(q)}{d q}>\frac{\partial \tilde{V}\left(q ; \rho_{\text {med }}\right)}{\partial q}$.

To interpret the condition that $\rho \frac{\partial^{2} x(q ; \rho)}{\partial \rho^{2}}$ should be increasing in $\rho$, a first-order Taylor approximation shows that the health effect of taxation can be written as

$$
-\delta \frac{\partial h(x(q ; \rho))}{\partial q}=\frac{\partial x^{*}(q ; \rho)}{\partial \rho} \simeq \frac{\partial x(q ; 0)}{\partial \rho}+\rho \frac{\partial^{2} x(q ; \rho)}{\partial \rho^{2}}
$$

Again, we therefore require that a price change affects the health of irrational consumers (heavy users) more than the health of rational consumers. 


\section{References}

Anderson, P., Baumberg, B., 2006. Alcohol in Europe - a public health perspective. London: Institute of Alcohol Studies.

Bernheim, B. D., Rangel, A. 2007. Behavioral Public Economics: Welfare and Policy Analysis with Nonstandard Decision-Makers. In Diamond, P., Vartiainen, H. (Eds.). Behavioral Economics and Its Applications. Princeton: Princeton University Press, 7-77.

Bovenberg, A. L., de Mooij, R. A., 1994. Environmental Levies and Distortionary Taxation. American Economic Review 94, 1085-1089.

Camerer, C., Issacharoff, S., Loewenstein, G., O’Donoghue, T., Rabin, M., 2003. Regulation for Conservatives: Behavioral Economics and the Case for "Asymmetric Paternalism". University of Pennsylvania Law Review 151, 1211-1254.

Cnossen, S., 2006a. Alcohol taxation and regulation in the European Union. CESifo Working Paper No. 1821.

Cnossen, S., 2006b. Tobacco taxation in the European Union. FinanzArchiv 62, 305-322.

Cnossen, S., Smart, M., 2005. Taxation of Tobacco. In Cnossen, S. (Ed.). Theory and Practice of Excise Taxation. Oxford: Oxford University Press.

Diamond, P. A., 1973. Consumption Externalities and Imperfect Corrective Pricing. Bell Journal of Economics and Management Science 4, 526-538.

Downs, A., 1957. An Economic Theory of Democracy. New York: Harper and Row.

Eerola, E., Huhtala, A., 2007. Voting for Environmental Policy Under Income and Preference Heterogeneity. American Journal of Agricultural Economics, forthcoming.

Epple, D., Romano, R. E., 1996. Public Provision of Private Goods. Journal of Political Economy 104, 57-84.

European Commission, 2004. Tobacco or Health in the European Union: Past, Present and Future. Brussels: the Aspect Consortium.

Gans, J. S., Smart, M., 1996. Majority Voting with Single-Crossing Preferences. Journal of Public Economics 59, 219-237.

Gaube, T., 2005. Financing Public Goods with Income Taxation: Provision Rules vs. Provision Level. International Tax and Public Finance 12, 319-334.

Glaeser, E. L., 2006. Paternalism and Psychology. University of Chicago Law Review 73, 133-156. 
Gruber, J., Köszegi, B., 2004. Tax Incidence when Individuals are Time-Inconsistent: the Case of Cigarette Excise Taxes. Journal of Public Economics 88, 1959-1987.

Gruber, J., Mullainathan, S., 2005. Do Cigarette Taxes Make Smokers Happier? Advances in Economic Analysis \& Policy 5, article 4.

Kimball, M. S., 1990. Precautionary Saving in the Small and in the Large. Econometrica 58, 53-73.

Köszegi, B., 2005. On the Feasibility of Market Solutions to Self-Control Problems. Swedish Economic Policy Review 12, 65-94.

Kotakorpi, K., 2006. The Incidence of Sin Taxes. Economics Letters, forthcoming.

Laibson, D., 1997. Golden Eggs and Hyperbolic Discounting. Quarterly Journal of Economics $112,443-477$.

O’Donoghue, T., Rabin, M., 2006. Optimal Sin Taxes. Journal of Public Economics 90, 18251849 .

O’Donoghue, T., Rabin, M., 2003. Studying Optimal Paternalism, Illustrated by a Model of Sin Taxes. American Economic Review (Papers and Proceedings) 93, 186-191.

O’Donoghue, T., Rabin, M., 2001. Choice and Procrastination. Quarterly Journal of Economics 116, 121-160.

O’Donoghue, T., Rabin, M., 1999. Doing it Now or Later, American Economic Review 89, 103-124.

Persson, T., Tabellini, G., 2000. Political Economics - Explaining Economic Policy. Cambridge, MA: MIT Press.

Pirttilä, J., Tenhunen, S., 2007. Pawns and Queens Revisited: Public Provision of Private Goods When Individuals Make Mistakes. International Tax and Public Finance, forthcoming.

Pollak, R.A., 1968. Consistent planning. Review of Economic Studies 35, 201-208.

Sandmo, A., 1975. Optimal Taxation in the Presence of Externalities. Swedish Journal of Economics 77, 86-98.

Strotz, R. H., 1955-6. Myopia and Inconsistency in Dynamic Utility Maximization. Review of Economic Studies 23, 165-80.

Thaler, R. H., Sunstein, C., 2003. Libertarian Paternalism. American Economic Review (Papers and Proceedings) 93, 175-179.

WHO (World Health Organization), 2004. Global Status Report: Alcohol Policy. Geveva: WHO Press. 